\title{
LAS ACTITUDES DE LOS ESPAÑOLES HACIA LAS POLÍTICAS SOCIALES
}

\author{
ANTONIO M. JAIME CASTILLO
}

Universidad de Granada

\author{
PALABRAS CLAVE ADICIONALES \\ ADDITIONAL KEYWORDS \\ Estado de Bienestar, Opinión pública, Política \\ Welfare State, Public Opinion, Social Policy. \\ social.
}

RESUMEN. Las actitudes hacia el Estado de Bienestar se han mantenido relativamente estables en la mayoría de los países occidentales en las últimas décadas. No obstante, se han producido importantes cambios en la concepción del papel del Estado en la sociedad y en el fundamento de los derechos sociales. En el caso español, conviven unas altas expectativas depositadas en el Estado, como ente benefactor y nivelador de las desigualdades percibidas en la sociedad, con una visión particularmente crítica de su capacidad para encarar y resolver los problemas. Con todo, el apoyo a la intervención del Estado a través de políticas sociales ha permanecido en niveles bastante altos durante la década de los noventa. $\mathrm{Y}$ estas actitudes se distribuyen casi por igual entre todos los segmentos de la sociedad española.

\section{INTRODUCCIÓN}

Desde la perspectiva comparada de las sociedades industriales avanzadas se pueden identificar dos tendencias básicas de opinión pública respecto al Estado de Bienestar y las políticas sociales en las dos últimas décadas. Por una parte, el

\footnotetext{
' El autor agradece las valiosas observaciones y sugerencias Julio Iglesias de Ussel a la versión preliminar de este trabajo. No obstante, asume toda la responsabilidad por los errores y omisiones contenidos en esta versión definitiva.
}

Revista Internacional de Sociología (RIS)

Tercera Época, ${ }^{\circ}$ 26, Mayo-Agosto, 2000, pp. 125-157. 
apoyo hacia las políticas sociales se ha mantenido estable en niveles relativamente altos en la mayoría de los países occidentales desde la década de los setenta (Bean y Papadakis, 1998; Kaase y Newton, 1995; Shapiro y Young, 1989). Pero, por otra parte, se ha producido una gran transformación en la forma en que los ciudadanos perciben la eficacia y efectividad de los sistemas de bienestar. En general, se ha dado un movimiento crítico hacia la forma en que los gobiernos gestionan los servicios de bienestar, del mismo modo que se ha producido un cambio en la concepción del papel del Estado en la sociedad y en el fundamento de los derechos sociales.

En cuanto a la tesis de la estabilidad, en estas dos últimas décadas han sido escasas las oscilaciones en el nivel de apoyo agregado a las políticas de bienestar. Varios países conocieron a finales de los años setenta y principios de los años ochenta un ligero decaimiento en el grado de aceptación del Estado de Bienestar, que algunos especialistas comenzaron a denominar como welfare baklash (o retroceso del apoyo popular al Estado de Bienestar). Esto sucedió así, por ejemplo, en Estados Unidos y Gran Bretaña, países en los que, además, hubo en esos años un intenso debate en torno al déficit crónico de los presupuestos públicos y las crecientes cargas fiscales soportadas por la ciudadanía.

Sin embargo, después de la llegada al poder de Ronald Reagan y Margaret Thatcher, la opinión pública volvió a mostrarse más partidaria del Estado de Bienestar en ambos países, probablemente ante la amenaza de su desmantelamiento (Shapiro y Young, 1989). Movimientos similares se produjeron también en los países escandinavos, especialmente en Noruega, donde el Partido Progresista capitalizó en 1973 el descontento ciudadano hacia la alta presión fiscal inducida por un elevado volumen de gasto público en programas sociales. En general, en la mayoría de los países europeos se dieron pequeñas oscilaciones en el nivel de apoyo a las políticas sociales, pero la tendencia ha permanecido relativamente estacionaria a lo largo de los años.

Como señalan Cnaan y sus colaboradores (1993), a pesar de que durante la última década se ha asumido generalizadamente que la legitimidad del Estado de Bienestar estaba en crisis, lo cierto es que los estudios empíricos han mostrado un soporte continuado hacia los principales programas de bienestar en los países occidentales. Sin embargo, existe un déficit de investigación en este campo que nos permita establecer comparaciones transnacionales.

No obstante, este marco general de las sociedades occidentales requiere algún tipo de matizaciones cuando nos referimos al caso español, que es particular en muchos sentidos. El desarrollo del Estado de Bienestar en España fue bastante más tardío que en el resto de los países occidentales. Durante el franquismo se produjo el desarrollo de un gran número de instrumentos de protección social, pero no llegó a institucionalizarse un Estado de Bienestar. Con la llegada de la democracia se van a impulsar las medidas para la creación de un Estado de Bienestar a la manera europea, dando el primer paso la Constitución de 1978 en cuyo 
artículo primero define a España como "un Estado social, democrático y de Derecho" y dedicando todo el Capítulo III de su Título I a consagrar los derechos sociales como derechos de la ciudadanía desde la óptica marshalliana.

Junto con este cambio en el marco normativo, también se produce en los años setenta un fuerte incremento en los gastos de protección social, un incremento que va a continuar con posterioridad a la transición democrática, aunque el crecimiento sea menos espectacular durante los años ochenta y noventa. En 1970 el gasto en prestaciones sociales en España alcanzaba el 8,8 \% del Producto Interior Bruto a precios de mercado, mientras que en 1994 este porcentaje rondaba el 23,6\%, habiéndose reducido, por otra parte, la diferencia con el resto de países europeos en la cuantía del gasto social (Barrada y Gonzalo, 1998).

\section{UNA NUEVA CONCEPCIÓN DEL PAPEL DEL ESTADO Y DE LOS DERECHOS SOCIALES}

$\mathrm{Al}$ margen de las pautas de estabilidad en las actitudes hacia el volumen de gasto en políticas sociales, también se han producido cambios notables en las actitudes de los ciudadanos occidentales con respecto al Estado y su función como benefactor. Hay que destacar que estos cambios han sido muchas veces pasados por alto al analizar la opinión pública en relación con el Estado de Bienestar, pues a menudo los analistas se han centrado en el nivel de apoyo global, incidiendo más en los elementos de estabilidad que de cambio. Sin embargo, no conviene minimizar la amplitud y dimensiones de estos cambios, los cuales se hayan relacionados con transformaciones de profundo calado que se han producido en las sociedades industriales avanzadas en las últimas décadas.

La percepción crítica de la gestión de los servicios de bienestar es un síntoma de un fenómeno más amplio: la evaluación negativa de la gestión gubernamental en todos los órdenes. Y "no se trata sólo de actitudes, sino también de comportamientos de hostilidad y protesta" (Murillo Ferrol, 1984). En efecto, varios autores han encontrado una estrecha relación entre las variaciones en el nivel de apoyo al Estado de Bienestar y los movimientos de protesta fiscal (tax revolt) que se sucedieron en varios países en la década de los setenta, como respuesta a los altos niveles de presión fiscal que soportaban las clases medias (Cnaan, 1993; Ladd et al., 1979; Smith, 1990).

Tom W. Smith (1990), después de constatar un giro conservador en la opinión pública norteamericana a mediados de la década de los setenta, ha argumentado que este giro conservador se encuentra relacionado con tres factores que caracterizaban la percepción del sistema de bienestar en ese momento: el incremento de la delincuencia en las grandes ciudades, el alto nivel de presión fiscal y la percepción de un fraude generalizado en los sistemas de provisión social. 
No es que las demandas dirigidas al estado se hayan atemperado. Antes al contrario, la propia dinámica de nuestras sociedades genera una espiral de expectativas de progreso y de realización de derechos, cuyo garante último es el Estado. Resulta obvio, además, que "ninguna sociedad que promete justicia y, habiendo admitido la legitimidad de las demandas, comienza lentamente a abrir el camino, puede luego abrigar la esperanza de controlar confortablemente el torbellino consiguiente" (Bell, [1976] 1994). Como señalaba Murillo Ferrol, esta revolución de las expectativas es una de las características más sobresalientes de la sociedad post-industrial y una causa concomitante de la crisis del Estado. Desde este punto de vista, "la cuestión puede verse como un problema de expectativas que crecen demasiado o no alcanzan a ser satisfechas" (Murillo Ferrol, 1984). Y en la línea de este argumento, varios autores han recurrido a la tesis de la frustración de las expectativas para tratar de explicar la actual crisis de confianza en las instituciones políticas (inter alia, López Pintor, 1997; Samuelson, 1995).

La ciudadanía sigue favoreciendo la asistencia colectiva a las necesidades individuales, en un grado bastante similar a como lo hacía veinte o treinta años atrás. Lo que han cambiado son las ideas acerca de cómo deben ser resueltos los problemas. La desconfianza en la gestión pública hace que mientras se apoya, por una parte, la atención a las personas con problemas, por otra, se ha extendido un sentimiento de recelo hacia el enorme volumen de gasto que gestionan los gobiernos. Por este motivo, las formas tradicionales de ayuda a los sectores desfavorecidos se perciben de forma bastante crítica, se rechaza abiertamente la producción pública de una amplia gama de bienes y servicios y se pide al gobierno que intervenga menos en la economía (Delgado y San Vicente, 1998). La mayoría de los estadounidenses, por ejemplo, están de acuerdo en incrementar la ayuda a los pobres, al tiempo que sostienen que habría que reducir el gasto del gobierno en programas de bienestar, precisamente porque los consideran una forma ineficiente de ayuda (Smith, 1987a; 1995).

Tom W. Smith afirma que el público no quiere penalizar o desatender a los pobres, sino proveerlos con más asistencia. Sin embargo, percibe de forma igualmente clara que el gasto tradicional en bienestar no es el mecanismo para proveer a los pobres con esa mayor ayuda. Así, "las personas quieren ser generosas como liberales, pero cuestionan los esfuerzos actuales del gobierno como conservadores" (Smith, 1995). Podemos argumentar con Yankelovich (1994) que la opinión pública occidental se ha vuelto más pragmático en la evaluación de la intervención del gobierno en la economía y en la vida social, en general. La gente ya no suele evaluar la intervención estatal en términos ideológicos, sino que tienden a apoyar la intervención del Estado allí donde se demuestra que ésta es eficaz y la rechaza donde no arroja resultados satisfactorios.

Para la mayoría de los problemas, se favorece tanto gasto adicional como sea necesario. Pero la sociedad quiere que el gasto sea efectivo, a fin de mejorar los problemas para los que estos gastos han sido previstos. "Más que menos gasto, 
lo que el público quiere es un gasto que funcione" (Smith, 1995). Los datos también parecen clarividentes a este respecto. Una mayoría de ciudadanos en las sociedades occidentales tiene una opinión bastante crítica del modo en que se gestionan los servicios públicos, y más concretamente los servicios de bienestar social.

En definitiva, la opinión pública aparece como más exigente con respecto a la gestión pública. En 1996, según una encuesta del Eurobarómetro, los europeos se mostraban mayoritariamente de acuerdo con la afirmación de que la mejora de la calidad de los servicios públicos es una tarea prioritaria para el futuro (Eurobarómetro, 1997). Del mismo modo, amplias mayorías de población en las democracias occidentales perciben que el balance entre lo que pagan en impuestos y los servicios que ofrece el Estado es claramente negativo (Botella, 1994). Y estas críticas son más intensas precisamente en aquellos lugares en los que más se habían desarrollado los sistemas públicos de bienestar, en los países escandinavos, donde se ha llegado a hablar de una uncivic culture, por oposición al otrora característico civismo de estos países, que los convirtió en un modelo de paz social (Murillo Ferrol, 1984).

Pero junto a esta tendencia que evoluciona en la dirección de demandar unos mejores criterios de asignación del gasto público a los gobiernos, Yankelovich (1994) también nos documenta otro cambio fundamental que se ha dado en la forma de entender y conceptualizar los derechos sociales. En los años sesenta, en pleno periodo de desarrollo económico, existía la convicción generalizada de que todo el mundo tenía derecho a disfrutar de todas las ventajas materiales que pudiera proporcionar la sociedad. Los derechos sociales se justificaban a partir de la noción de necesidad. Sin embargo, en los años noventa estamos presenciando un cambio en la concepción de los derechos, hacia una nueva filosofía basada en la reciprocidad. Es decir, que hemos de procurar ayuda a cada individuo que lo necesite, pero a cambio de exigir una contraprestación cuando ésta sea posible.

Desde una perspectiva europea, Sartori (1993) advierte que uno de los graves peligros que acechan a la democracia es la idea ingenua de que los derechos sociales son naturales y absolutos. Muy al contrario, los derechos sociales son derechos a cosas materiales y, como tales, dependen de la capacidad de una sociedad para generar los suficientes recursos materiales para atenderlos. Las demandas materiales no tienen un límite precisable y, por tanto, todo puede ser demandado, en base a la idea de que es necesario. Argumentos similares fueron expuestos ya por Daniel Bell ([1976] 1994; 1977) en la década de los setenta al hacer referencia a la "revolución de los títulos en ascenso" en el marco de su teoría de las contradicciones culturales del capitalismo. 


\section{ACTITUDES DE LOS ESPAÑOLES SOBRE EL MODELO DE SOCIE- DAD Y EL PAPEL DEL ESTADO}

El marco en el que hemos de analizar las actitudes básicas de los españoles hacia las políticas sociales lleva a plantearnos algunas cuestiones previas sobre la mentalidad de los españoles en relación con el papel del estado. Como ha sido destacado en varias ocasiones, en el caso español convive un pronunciado distanciamiento entre los ciudadanos y sus instituciones políticas con una visión extendida del Estado como garante de un amplio abanico de necesidades (Morán y Benedicto, 1995). Y es que el español fía poco en un Estado del que espera mucho y al que pide mucho, pero que, según su entender, es "sinónimo de arbitrariedad, despilfarro y mala administración" (Murillo Ferrol, 1984). En este mismo sentido, se ha afirmado que el Estado español "es depositario de grandes expectativas pero, al mismo tiempo, se desconfía de su capacidad para satisfacerlas. El imaginario colectivo español viene concibiendo al Estado como un gran benefactor que debe resolver las necesidades de todos los ciudadanos, lo que no obsta para que se piense que es incapaz de gestionar con eficacia y eficiencia los temas de su competencia" (Delgado y SanVicente, 1998).

Para Murillo Ferrol, esta aparente paradoja entre altas expectativas y bajo nivel de confianza se explica por la débil asimilación del Estado en nuestra cultura, lo cual se traduce, en última instancia, en la carencia de legitimación profunda e interiorización del Estado como mecanismo de gobierno colectivo. Esta falta de asimilación se ha plasmado desde antaño en la desconfianza secular hacia la burocracia y el sistema judicial o en la conciencia generalizada de fraude y evasión en la recaudación y la gestión de los dineros públicos. No es sólo que no exista una conciencia colectiva de lo público, sino que se considera al Estado como una entidad extraña al individuo, "a la que se puede, y aun se debe, eludir, defraudar e ignorar en la medida de lo posible. Sin perjuicio, naturalmente, de hacerla núcleo de imputación cuando se trate de obtener algo de ella" (Murillo Ferrol, 1984).

En términos similares se expresaba Salustiano del Campo, para quien "nuestra sociedad adolece, frente a otras de más larga tradición democrática, de una dependencia excesiva del Estado" (Campo, 1995). En 1988, por ejemplo, un $75 \%$ de los españoles opinaba que el Estado es responsable del bienestar de todos los ciudadanos y debe ocuparse de todas aquellas personas que tienen dificultades. Por el contrario, sólo el $44 \%$ de los franceses suscribían esta opinión y apenas un $26 \%$ de los estadounidenses. Según puede comprobarse, este sentimiento de proteccionismo estatal en España no está condicionado por la ideología, sino que impregna a los votantes de todos los partidos por igual (Toharia, 1989).

La tendencia se ha mantenido en los años sucesivos. En 1991, en una encuesta del CIRES, un $86 \%$ de los entrevistados respondían de forma positiva ante la cuestión de si el Estado ha de garantizar las necesidades básicas de todos los 
ciudadanos. En 1995, un estudio del CIS mostraba a un 76\% de los españoles de acuerdo con la idea de que el Estado es responsable del bienestar de todos los ciudadanos y debería ocuparse de los que se encuentren en situación de necesidad. Y en otra encuesta del CIS de 1996, un 87\% de los entrevistados ratificaban la idea de que el Estado tiene que cubrir las necesidades básicas de todos los ciudadanos, al mismo tiempo que un $78 \%$ manifestaba que el Estado debería garantizar unos ingresos mínimos a todos los individuos.

Otro valor que está estrechamente relacionado con las actitudes hacia las políticas sociales es el de la igualdad, en este caso igualdad social y económica. En perspectiva comparada, los españoles, junto con los demás países mediterráneos, siguen apareciendo como los más igualitaristas de Europa, aunque durante la década de los ochenta se produce una ligera tendencia hacia el polo de la libertad. Así, por ejemplo, en la Encuesta Mundial de Valores de 1992, los españoles aparecían más inclinados hacia la libertad que los italianos. Pero las diferencias con el resto de los países europeos se mantienen, a pesar de un relativo proceso de convergencia (Andrés Orizo, 1994).

En efecto, "la tendencia hacia la libertad como valor que predomina sobre la igualdad se había incrementado desde 1981. Sin embargo, los resultados de un estudio nacional realizado en diciembre de 1992 han demostrado un cambio en esta tendencia" (Campo, 1995). A principios de los años noventa se había producido la cima en la valoración de la libertad como valor frente al de la igualdad en la sociedad española. Según datos del CIRES, en 1993 el porcentaje de españoles que preferían la libertad a la igualdad representaba un $60 \%$, pero desde este año en adelante se va a producir un reforzamiento de las ideas de igualdad frente a las de libertad, descendiendo hasta el 54\% el porcentaje de los que preferían la libertad frente a la igualdad en 1996 (vid. gráfico 1).

Un movimiento paralelo se da en el eje de preferencias entre la igualdad de oportunidades y el bienestar económico. En 1992, según los datos del CIRES, era un $61 \%$ de los españoles el que anteponía la igualdad al bienestar económico, mientras que en 1994 este porcentaje se había elevado hasta el 69\%, aunque descendió ligeramente en 1995 y 1996. Según ha resaltado Andrés Orizo (1996), los españoles prefieren repartir pobreza en el presente antes que afrontar los sacrificios necesarios para generar una mayor riqueza colectiva e individual en el futuro.

La crisis económica, con sus efectos sobre el nivel de paro, parece estar detrás de este repunte de los valores de la igualdad. Salustiano del Campo iba más lejos al afirmar que la crisis también había puesto de manifiesto "las grandes diferencias que se dan todavía hoy entre las distintas capas de la estructura social española y las carencias que un sistema puramente liberal puede producir a corto plazo" (Campo, 1995). Para este autor, la percepción de las desigualdades se ha visto amplificada por ciertos ejemplos de rápidos y fraudulentos enriquecimientos en círculos cercanos al poder, que han reforzado la opinión de que el origen de 
Gráfico 1.

Preferencia por igualdad o libertad

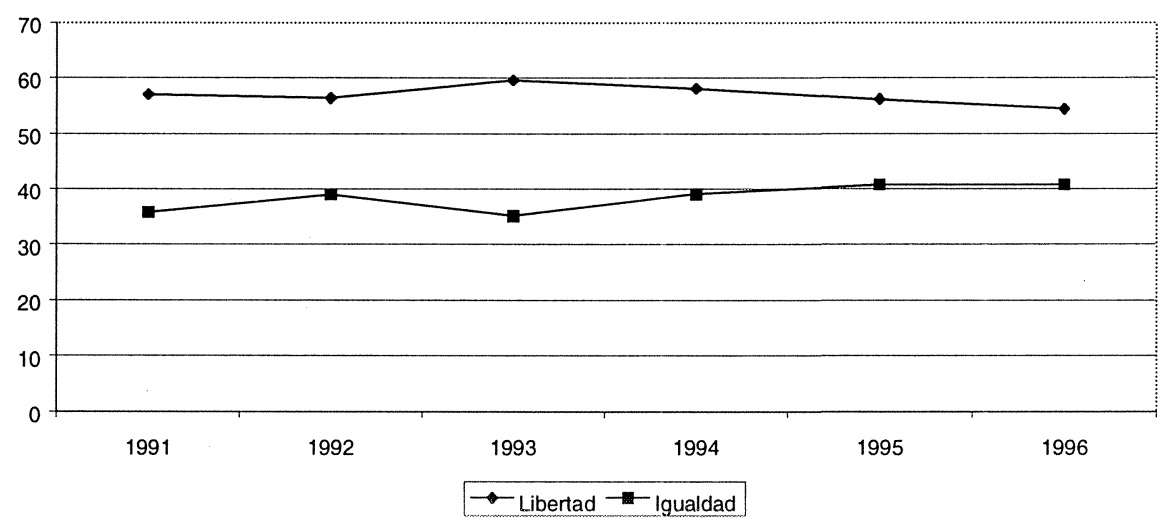

Fuente: Encuestas de Cultura Política y Económica del CIRES (1991-1996).

las desigualdades es básicamente injusto y de que éstas no dependen, al menos fundamentalmente, del trabajo o el esfuerzo individual.

En el terreno de las realidades concretas, durante la primera mitad de la década de los noventa, un porcentaje variable entre el $75 \%$ y el $80 \%$ consideraba que las desigualdades existentes en la sociedad española son grandes o muy grandes. Del mismo modo, otro porcentaje cercano al $80 \%$ manifiestaba que esas desigualdades son injustas o muy injustas, coincidiendo, además, en 1993 y 1994 los años en los que un porcentaje más alto resaltaba la magnitud de las desigualdades existentes en el país, al tiempo que un mayor número de personas las calificaba como injustas. El español "piensa que vive en una sociedad muy piramidal (...), cuando su aspiración es vivir en una sociedad en rombo (...) similar a la que cree propia de los países más prósperos y desarrollados de la Unión Europea. Este cambio social sería responsabilidad del Estado" (Delgado y San Vicente, 1998). En 1996, por ejemplo, el 74\% de los entrevistados en una encuesta del CIS decía estar de acuerdo o muy de acuerdo con la idea de que el Estado tiene la responsabilidad de reducir las diferencias de ingresos existentes en la sociedad española.

En consonancia con esta tónica, las preferencias por la intervención del Estado se mantienen en niveles relativamente estables. Según los datos del CIRES, en 1996 casi una tercera parte de los españoles se mostraba partidaria de que el Estado interviniese algo más, mientras que una cuarta parte se mostraba partidaria de que el Estado interviniese bastante o mucho más. En el lado opuesto, uno de cada cinco opinaba que el Estado debería intervenir algo menos y sólo uno de 
cada diez que debería intervenir bastante o mucho menos. Y es obvio que "este claro predomino, en nuestra sociedad, de orientaciones valorativas de base de corte socialista-comunitario más que capitalista-individualista se traduce, lógicamente, en un debilitamiento de la sociedad civil" (Toharia, 1989).

Wert (1996), por su parte, se hacía eco de que la amplia mayoría de los españoles, sin distingos de clase o ideología, son partidarios de un modelo "estatal asistencial", cuyos pilares básicos son la reducción de las desigualdades y la asistencia a los desfavorecidos, por oposición a un modelo "competitivo-liberal", basado en los valores del individualismo económico, que es el que ha venido produciendo los resultados económicos más eficientes en las sociedades de nuestro entorno geopolítico. Y concluía que "el aprendizaje de la incompatibilidad entre el modelo preferido y el discurso de orden de la realidad va a resultar penoso en los años por venir" (Wert, 1996).

Aun a pesar de este panorama, apuntan signos de cambio, después de varias décadas de transformación acelerada de la sociedad española, en las que se ha producido un notable proceso de convergencia con el resto de Europa: "los valores económicos del mercado, de la competencia entre las personas, del trabajo y de la propiedad privada se están difundiendo de forma importante entre amplios sectores de la población" (Campo, 1995). Como consecuencia de la difusión de estos valores, se produce una tendencia que refuerza el papel del esfuerzo individual en la consecución de los objetivos personales, decreciendo la importancia atribuida a las relaciones de tipo particularista que han caracterizado a la sociedad española.

\section{ACTITUDES DE LOS ESPAÑOLES HACIA LAS POLÍTICAS SOCIALES}

En el marco de las investigaciones comparadas se suelen emplear varios indicadores referidos a las actitudes de los ciudadanos ante las políticas sociales. Normalmente, no obstante, se utiliza como indicador el nivel de apoyo al gasto público en cada una de estas políticas (inter alia, Bean y Papadakis, 1998; Shapiro y Young, 1989; Smith, 1995). Es un indicador adecuado para aproximarse a las actitudes hacia cada una de las políticas sociales, puesto que expresa la intensidad con la que la población defiende la necesidad de que el Estado realice, de manera general, un esfuerzo presupuestario en la dotación de estas políticas.

Cnaan (1989), sin embargo, ha puntualizado que se trata de un indicador imperfecto, puesto que no tiene en cuenta otras dimensiones de làs actitudes hacia el Estado de Bienestar. Cnaan descompone las actitudes hacia cada política concreta en tres indicadores: actitudes hacia el nivel de gasto público, actitudes hacia el número de beneficiarios del Estado de Bienestar y actitudes hacia la calidad de los servicios prestados. Dada la disponibilidad de datos estadísticos, este apartado se va a centrar en el análisis de las actitudes de los españoles hacia 
el volumen de gasto dedicado a las principales políticas sociales del Estado de Bienestar. En el apartado siguiente, no obstante, se abordará el tema de las actitudes hacia la calidad de los servicios públicos, aunque sea de forma genérica. Los datos utilizados provienen fundamentalmente de las encuestas de Cultura Política y Económica realizadas por el CIRES entre los años 1991 y 1996.

\section{Hipótesis interpretativas sobre los factores que determinan las actitudes hacia las políticas sociales}

Los estudios que se han centrado en el análisis de los factores que determinan las actitudes hacia el Estado de Bienestar son relativamente escasos (Cnaan, 1993; Shapiro y Young, 1989; Smith, 1987b). No obstante, la investigación comparada ha hallado algunas pautas recurrentes que merece la pena traer a colación para estudiar el caso español. Existe una primera corriente de investigación que ha tratado de relacionar las actitudes de cada individuo concreto hacia el Estado de Bienestar con la posición que ocupa ese sujeto en la estructura social. Otro segundo grupo de teorías consideran las actitudes hacia el Estado de Bienestar como un subproducto ideológico y, por este motivo, tratan de relacionarlas con las características ideológicas de los individuos, tales como su posición en el continuum izquierda-derecha, sus valores sociopolíticos, sus afinidades partidistas, etcétera.

Dentro de la primera corriente de investigación, hay autores que argumentan que el grado de preferencia por las políticas sociales es más alto entre aquellas personas que se encuentran en los escalones más bajos de la sociedad, puesto que ellos son los más necesitados de ayuda. Es la tesis que se conoce como underdog hypothesis (de los desvalidos). Para otros autores, sin embargo, sucede justo al revés. Los miembros de la clase trabajadora son los más reacios a apoyar las políticas sociales como una forma de autodefensa psicológica, tratando así de diferenciarse de los que se encuentran por debajo de ellos en la escala social, o aceptando como legítimas las diferencias sociales en un intento de asimilarse a las clases altas (Cnaan, 1993). Consideran que los beneficiarios de las políticas sociales son personas holgazanas, que prefieren los beneficios sociales al trabajo duro. Es la tesis que se conoce como working-class anger hypothesis (de la cólera de la clase obrera).

Lo cierto es que en la investigación empírica se han encontrado evidencias a favor de uno y otro planteamiento. Así, por ejemplo, el estudio clásico de Robert E. Lane (1959) mostró que el apoyo a los programas de bienestar era más intenso entre los individuos con alto nivel educativo y una clase social elevada. A parecidas conclusiones llegaba otro estudio clásico más reciente de Peter TaylorGooby (1983) en Inglaterra.

No obstante, los estudios más amplios a nivel comparativo han hallado que los individuos más propensos a apoyar las políticas de bienestar se encuentran 
entre los grupos más desfavorecidos de la sociedad, los de status socioeconómico más bajo y en algunas sociedades, como Estados Unidos, además, los que pertenecen a minorías étnicas o raciales. En la mayoría de los países de Europa, por otro lado, la edad es una variable importante en la determinación de las actitudes hacia el Estado de Bienestar, ya que los jóvenes se suelen mostrar más partidarios de las políticas sociales que las personas de edad más avanzada, una relación que no suele darse en Estados Unidos (inter alia, Shapiro y Young, 1989).

Sobre las teorías de la determinación ideológica de las actitudes hacia las políticas sociales, la evidencia disponible resulta más cuestionable y menos convincente. En Estados Unidos, por ejemplo, la afinidad partidista ha servido históricamente para diferenciar a los partidarios del Estado de Bienestar. Pero esto sólo es así cuando las cuestiones de política social adquieren suficiente relevancia en el debate político entre los partidos (Shapiro y Young, 1989). Según una tesis ampliamente aceptada, el realignment que se produjo en la política norteamericana en los años treinta fue provocado por la entrada en el electorado de una nueva generación de votantes, más orientada hacia las políticas de bienestar propugnadas por la administración demócrata del New Deal. En cualquier caso, como señalan Cnaan y colaboradores (1993), estas teorías no han podido establecer con claridad la relación entre la ideología y el status socioeconómico, ni la relación de ambos factores con las actitudes hacia el Estado de Bienestar.

Gráfico 2.

Entidad responsable de asegurar determinados derechos.

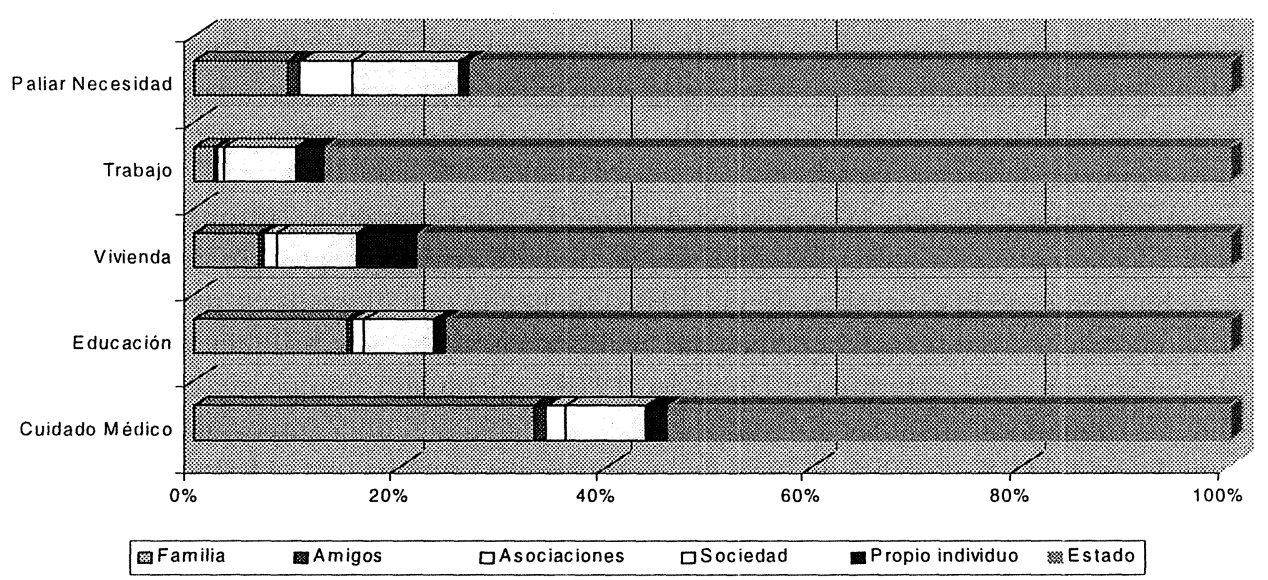

Fuente: Encuesta de Bienestar Social del CIRES (1994). 
Para el caso español no disponemos de estudios de entidad que se hallan dirigido a comprobar estas hipótesis. Un examen de los datos analizados en este trabajo muestra que las actitudes de los españoles parecen no adecuarse muy bien a ninguna de las tres hipótesis expuestas. Más bien al contrario, la mentalidad de apoyo a la intervención del Estado, a través de políticas sociales redistributivas, impregna a todos los segmentos de la sociedad casi por igual, lo cual va en concordancia con las actitudes hacia el Estado examinadas.

El status socioeconómico aparece relacionado con las actitudes hacia algunas políticas sociales. Parece que conforme se desciende de clase social aumenta la inclinación a incrementar el gasto en algunas políticas sociales, pero los efectos no son lineales ni intercambiables entre unas políticas y otras. Otro tanto cabe decir de la relación con la variable del nivel de ingresos. Ideológicamente sí que se aprecia una ligera asociación entre posiciones de izquierda y mayor apoyo al gasto en determinadas políticas sociales, pero es una relación que no se verifica en el estudio de las actitudes hacia todas las políticas sociales. La edad, sin embargo, parece tener un efecto recurrente en varias áreas de la política social. Normalmente, los jóvenes y los mayores son los menos propensos a apoyar el gasto en política social, siendo los más predispuestos los individuos de edades intermedias.

\section{Pensiones de jubilación}

La Seguridad Social es, probablemente, la institución sobre la que se vertebra el Estado de Bienestar moderno. Y la garantía de unos niveles de vida dignos para los trabajadores una vez alcanzada la edad del cese de la actividad productiva es uno de los objetivos primordiales de los sistemas de Seguridad Social contemporáneos. En España la garantía de unas pensiones dignas y adecuadas para la tercera edad aparece recogida en el artículo 50 de la Constitución de 1978. Por otro lado, desde los años de la transición democrática en adelante, se han ampliado los instrumentos de tipo contributivo y no contributivo para la protección de la tercera edad.

A ello hemos de unir la evolución demográfica del país en las últimas décadas. El porcentaje de población jubilada ha crecido notablemente debido al ensanchamiento de la esperanza de vida. Esto ha hecho que el gasto en pensiones haya pasado del medio billón de pesetas en 1978 a los casi siete billones y medio de pesetas en 1995 (Barrada y Gonzalo, 1998). Al mismo tiempo, se constata que las demandas dirigidas al Estado en este capítulo son muy importantes. Según datos del CIS, en 1996 el 79 \% de los españoles opinaba que el Estado tenía la obligación de garantizar unas pensiones adecuadas para todos los ciudadanos. Y en la encuesta de bienestar de la ONCE del mismo año, un 84\% de los españoles suscribía que las administraciones públicas eran responsables de asegurar el derecho a recibir ayuda en la vejez (vid. en Muñoz Machado et al., 1997). 
Es por este motivo que, a pesar del aumento del gasto en este capítulo del presupuesto estatal y del porcentaje de beneficiarios, durante la década de los noventa la impresión generalizada es que se gasta poco en pensiones de jubilación, aunque se aprecia una tendencia al aumento de quienes consideran que el montante gastado es el idóneo. En efecto, se pasa de un 65\% que en 1991 consideraba que el Estado gastaba demasiado poco en pensiones de jubilación, frente a un 24\% que consideraban que el gasto era suficiente, a un 56\% que en 1996 pensaba que el gasto era demasiado poco y a un 35\% que tenían la impresión de que el gasto era suficiente (gráfico 3).

Con todo, existen notables diferencias de actitud en cuanto a la percepción del gasto público en pensiones (tabla 1). La edad, como era previsible, es una de las variables que más influye en la opinión respecto a esta partida del gasto social. En la media del periodo analizado, entre los jóvenes de 18 a 25 años, sólo un 56,5\% sostiene que el gasto público en pensiones de jubilación era demasiado escaso, mientras que esta misma afirmación es compartida por un $68,9 \%$ de los que tienen más de 60 años.

Algunos autores han apelado, con frecuencia, a la tesis del auto-interés para explicar la relación positiva entre edad y las actitudes favorables hacia el gasto en pensiones, puesto que los ancianos son los beneficiarios y los jóvenes son quienes tienen que pagar las pensiones en un sistema de reparto como el español. Sin embargo, Shapiro y Young (1989) han afirmado que, de acuerdo con la tesis del auto-interés, los jóvenes también habrían de mostrarse propensos a apoyar los gastos en pensiones porque eso permite a las generaciones ancianas tener una vida más autosuficiente, sin que tengan que depender de la generación de los hijos.

No obstante, las actitudes con respecto a esta política social se relacionan con otras variables. La relación con el nivel educativo no es lineal, pero se observa una ligera tendencia en el sentido de que a medida que desciende el nivel educativo de los entrevistados se incrementa la percepción de que el gasto en pensiones es demasiado escaso. En concreto, en el grupo de los que no tienen estudios, un $67,9 \%$ piensa que el Estado gasta demasiado poco en pensiones, mientras que esto sólo lo mantiene un 58,2\% en el grupo de los que han completado estudios universitarios. Esta relación puede tener una explicación de tipo psicológico, en el sentido de que las personas con mayores niveles educativos tienden a sentirse más seguras, y las personas con menor nivel educativo tenderían a desconfiar más del futuro.

Por lo que respecta al nivel de práctica religiosa, se constata que son los extremos, es decir, tanto los no practicantes como los muy practicantes, los que suscriben con mayor intensidad la afirmación de que el gasto en pensiones de jubilación es demasiado bajo. Otro tanto sucede con la ideología. Son aquéllos que se califican como más extremos ideológicamente, tanto por la izquierda como por la derecha, los que más insuficiente consideran el gasto en pensiones, frente a una opinión moderadamente más positiva de los que se sitúan en el centro de la escala ideológica. 
Gráfico 3.

Porcentaje de españoles que consideran que el gasto público es demasiado poco en distintas políticas sociales.

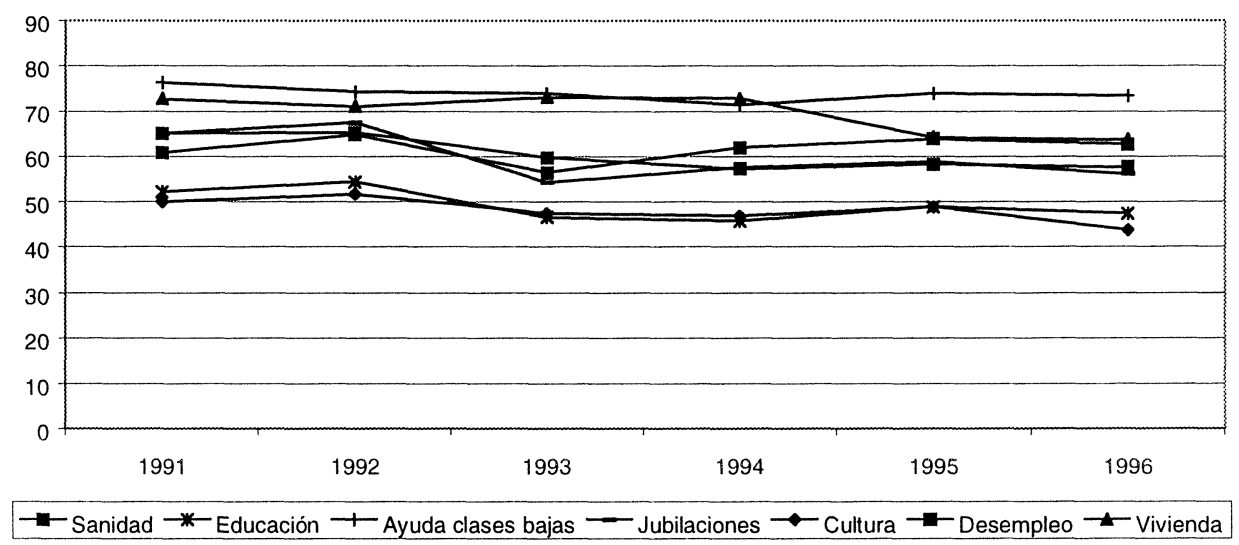

Fuente: Encuestas de Cultura Política y Económica del CIRES (1991-1996).

La asociación de la actitud hacia el gasto público en pensiones con la variable de clase social subjetiva aparece como más lineal. Cuanto más alta es la autopercepción de la clase social, menos proclives resultan los españoles a afirmar que el gasto en pensiones es demasiado bajo. Esto es lógico si se tiene en cuenta que son las clases sociales más altas las que tienen más posibilidades de ahorro de cara a la jubilación, por oposición a las clases bajas, que tienen una dependencia, casi exclusiva, de los ingresos procedentes de las pensiones públicas durante su jubilación. No obstante, quienes se autocalifican como de clase alta tienen una percepción más crítica del volumen de gasto que quienes se ubican en la clase media-alta.

Más allá de la demanda de mayores niveles de gasto en este capítulo de las políticas sociales, los españoles también se muestran partidarios de reformas profundas del sistema de pensiones, como pueda ser la introducción de un sistema privado complementario manteniendo el sistema público para asegurar un mínimo vital a todas las personas (Pérez Díaz et al., 1997). Y ello porque la opinión sobre el futuro del sistema público de pensiones es bastante negativa. Un 43\% de los españoles consideraba en 1996 que, dentro de 20 años, probablemente, no se va a poder contar con pensiones públicas del nivel de las actuales (Pérez Díaz et al., 1997). 
Tabla 1.

Actitudes de los españoles hacia el gasto público en pensiones de jubilación, por características sociodemográficas (\%).*

\begin{tabular}{lccc}
\hline & Demasiado poco & Suficiente & Demasiado \\
\hline Edad & & & \\
& & & \\
De 18 a 25 años & 56,5 & 36,7 & 6,7 \\
De 26 a 40 años & 61,9 & 34,1 & 4,0 \\
De 41 a 60 años & 64,7 & 32,2 & 3,1 \\
Más de 60 años & 68,9 & 27,8 & 3,3 \\
& & & \\
Nivel educativo & & & \\
& & 27,8 & 4,3 \\
Sin estudios & 67,9 & 33,2 & 5,1 \\
Estudios Primarios & 63,6 & 34,7 & 4,7 \\
Formación Profesional & 59,6 & 33,2 & 3,8 \\
Bachiller & 62,1 & 38,0 &
\end{tabular}

Religiosidad (1=No practicante; 5=Muy practicante)

$\begin{array}{llll}1 & 65,5 & 30,4 & 4,1 \\ 2 & 61,5 & 34,1 & 4,3 \\ 3 & 62,2 & 33,9 & 3,9 \\ 4 & 61,8 & 34,1 & 4,2 \\ 5 & 64,6 & 31,6 & 3,7\end{array}$

Ideología

$\begin{array}{llll}\text { Extrema Izquierda } & 68,3 & 27,5 & 4,2 \\ \text { Izquierda } & 64,8 & 31,8 & 3,4 \\ \text { Centro Izquierda } & 59,7 & 35,8 & 4,6 \\ \text { Centro } & 61,6 & 35,0 & 3,4 \\ \text { Centro Derecha } & 61,0 & 35,2 & 3,8 \\ \text { Derecha } & 62,3 & 31,5 & 6,3 \\ \text { Extrema Derecha } & 69,2 & 25,6 & 5,2\end{array}$

Clase social subjetiva

\begin{tabular}{llll} 
Alta & 61,1 & 30,6 & 8,3 \\
Media alta & 53,9 & 40,7 & 5,4 \\
Media media & 63,6 & 32,2 & 4,3 \\
Media baja & 63,2 & 32,9 & 3,8 \\
Baja & 65,0 & 31,9 & 3,1 \\
\hline
\end{tabular}

* Los porcentajes representan la media del periodo analizado (1991-1996) para cada categoría. Fuente: Encuestas de Cultura Política y Económica del CIRES (1991-1996). 


\section{Educación y Cultura}

La educación es otro de los servicios básicos que provee el Estado en la mayoría de las sociedades modernas. En la mayoría de estos países, la educación se ha ido convirtiendo en una función estatal a lo largo de todo este siglo al ser arrebatada progresivamente del control de las instituciones religiosas en un proceso paralelo al de secularización. Y a pesar de que en todos los países occidentales sigue conviviendo la enseñanza pública con la privada, bien sea laica o religiosa, el derecho a la educación se considera una forma de promoción social que debe ser garantizada por los poderes públicos.

En la Constitución española de 1978, por ejemplo, el derecho a la educación aparece reconocido en su artículo 27, dentro del capítulo dedicado a los derechos y libertades fundamentales de los ciudadanos. Del mismo modo, el artículo 44 hace referencia a la necesidad de que los poderes públicos promuevan el desarrollo de la cultura. También son numerosas las reformas legislativas que ha conocido el sistema educativo español, especialmente en los años posteriores a la transición política, la última de ellas la LOGSE.

La puesta en marcha de estas reformas educativas ha suscitado importantes debates políticos. De una parte con la Iglesia católica, fundamentalmente por el tema de la enseñanza de la religión. Y, por otro lado, los debates han girado en torno a la escasez de los recursos públicos dedicados a la implementación de estas reformas. Todo ello a pesar del esfuerzo presupuestario que se ha hecho en este campo. Baste señalar que el gasto público en educación pasó de ser aproximadamente un cuarto de billón de pesetas en 1978 a los dos billones y tres cuartos en 1995 (Barrada y Gonzalo, 1998).

Los españoles también se muestran mayoritariamente a favor de un sistema educativo garantizado con fondos públicos. Según una encuesta del CIRES de 1994, el $75 \%$ de los entrevistados opinaba que el Estado era el responsable de garantizar el derecho a la educación (vid. gráfico 2), una proporción que se mantenía en el $70 \%$ en la encuesta de bienestar de la ONCE en 1996. Sin embargo, el examen de las actitudes respecto del gasto en educación y cultura revela que es una cuestión que no preocupa excesivamente a los españoles. Ambas son las partidas del gasto social sobre las que se muestran relativamente más satisfechos, con una tendencia prácticamente coincidente.

En 1991, eran un 52\% los españoles que pensaban que el gasto educativo era demasiado pequeño, frente al $36 \%$ que lo consideraba suficiente. Más aún, la tendencia es hacia un énfasis relativamente menor sobre la necesidad del gasto en educación, puesto que en 1996, al final del periodo analizado, eran un $47 \%$ los que sostenían que el gasto era demasiado poco, frente al $44 \%$ que lo consideraba suficiente. Y en 1994 el porcentaje de los que mantenían esto último había superado ligeramente al de los que consideraban que el gasto era demasiado reducido (gráfico 3). 
Las actitudes hacia el gasto en educación se relacionan con la edad en una curva en forma de $U$ (tabla 2). El grupo más joven y el de los mayores de 60 años son los más satisfechos con el volumen actual de gasto en educación, superando, en el grupo de más de 60 años, los que consideran que el gasto es suficiente a los que consideran que es demasiado poco. Por el contrario, en los grupos de edad intermedios, de 26 a 40 años y de 41 a 60, los que consideran que el gasto es demasiado reducido superan claramente a los que opinan que el gasto es el adecuado.

También existe una asociación clara de las actitudes hacia el gasto en educación con el nivel educativo, como cabría esperar. Los más educados son los que consideran más insuficiente el gasto en educación, probablemente porque conocen mejor el sistema educativo y son conscientes de sus carencias. O precisamente porque son quienes más tiempo han dedicado a la formación, valoran más la educación y, por tanto, perciben la necesidad de un abundante respaldo presupuestario.

El nivel de práctica religiosa apenas condiciona las actitudes hacia el gasto en educación, si bien se observa que los no practicantes son quienes consideran en mayor proporción que el gasto en educación es insuficiente. Por otro lado, los grupos más extremos ideológicamente, de izquierda y derecha, aparecen nuevamente como los más insatisfechos con el montante del presupuesto público dedicado a educación. Y finalmente, la clase social subjetiva parece correlacionada positivamente con la actitud hacia el gasto en educación, es decir, que cuando se sube de clase social crecería el porcentaje de los que consideran insuficiente esta partida del presupuesto. Sin embargo, a pesar de esta tendencia general, el grupo de clase alta es el menos crítico con el volumen de dinero invertido en educación.

Las actitudes hacia el gasto del estado en cultura son prácticamente coincidentes con lo expuesto sobre el gasto en educación. En 1991, eran un 50\% los que sostenían que el gasto en cultura era demasiado poco, frente al $36 \%$ que lo consideraban suficiente. En 1996, sin embargo, los satisfechos con el gasto en cultura superaban a los que lo consideraban insuficiente, siendo los primeros un $45 \%$ y los últimos un $44 \%$.

Del mismo modo se verifica la relación en forma de $U$ de la actitud hacia el gasto en cultura con la edad (tabla 2). Los jóvenes y los ancianos tienden a considerar como suficiente el gasto en cultura, por oposición a los grupos de edades intermedias, que se muestran más críticos. También son los individuos de mayor nivel educativo los que lo consideran más insuficiente. No obstante, se observa una peculiaridad. La actitud hacia el gasto en cultura está relacionada linealmente con la ideología y la clase social subjetiva. Por lo que se refiere a la ideología, cuanto más a la izquierda se sitúan los españoles más insuficiente consideran el gasto en cultura. Y por lo que hace a la clase social subjetiva, son los individuos que se ubican en una posición de clase más elevada los que juzgan más escaso el gasto cultural. 


\section{Desempleo}

Otra de las políticas centrales del Estado de Bienestar es la asistencia a los desempleados o la protección pública contra las eventualidades de la interrupción temporal de la actividad productiva. En el caso español, la atención al desempleo es un problema de primera magnitud, debido a que se trata del país de la Unión Europea con la tasa más alta de paro. En respuesta a esta situación, y a pesar de que se han restringido las posibilidades de acceso a algunos tipos de prestaciones, los gastos en prestaciones por desempleo también han crecido de forma notable en las últimas décadas, pasando de los poco más de $300.000 \mathrm{mi}$ llones de pesetas de 1978 a los más de dos billones y medio en 1995.

Los ciudadanos, además, reclaman un papel activo del gobierno en este terreno. No es sólo que un $57 \%$ reclame un subsidio digno para los parados, según los datos de la citada encuesta del CIS de 1996, sino que otro $60 \%$ afirman que es labor del gobierno crear un puesto de trabajo para todo aquél que lo demande. En el mismo sentido se manifestaban los entrevistados en una encuesta del CIRES en 1994. Un $85 \%$ de los encuestados en esta ocasión opinaban que era el Estado quien debía garantizar el derecho al trabajo (gráfico 2), y un $82 \%$ se pronunciaba en el mismo sentido en la encuesta de bienestar de la ONCE de 1996.

Respecto de las actitudes hacia el gasto en desempleo, se observa que una mayoría considerable de los españoles, cercana o superior al $60 \%$ dependiendo de los años, opina que lo gastado en esta partida es demasiado poco. En 1991, en concreto, eran un $61 \%$ los que tenían esta impresión por oposición al $26 \%$ que manifestaban que el gasto en desempleo era suficiente. En 1993, sin embargo, el porcentaje de los que pensaban que el gasto era demasiado reducido disminuyó hasta el 56\%. No obstante, en 1996 este porcentaje volvía a situarse en el 63\%, siendo un $27 \%$ los que en este último año percibían el nivel de gasto en desempleo como suficiente (gráfico 3 ).

Las actitudes hacia el gasto en desempleo se relacionan claramente con la edad (tabla 3). Los jóvenes, como no podía ser de otra forma, tienden a pensar en mayor proporción que el gasto destinado a resolver el problema del paro es escaso. Y ello es comprensible si tenemos en cuenta que son el grupo de edad más afectado por este problema, con un grave problema de inserción en el mercado laboral.

El nivel educativo no condiciona de forma apreciable las actitudes hacia el gasto en desempleo, si bien se pueden identificar grupos especialmente críticos con el volumen de gasto en desempleo, como el de los que tienen estudios primarios. Lo mismo ocurre con la variable de clase social subjetiva, que no tiene un efecto muy llamativo sobre la distribución de las actitudes ante el gasto público en desempleo.

El nivel de práctica religiosa, por el contrario, sí correlaciona con las actitudes hacia el gasto en desempleo, coincidiendo los sectores de menor práctica 
Tabla 2.

Actitudes de los españoles hacia el gasto público en educación y cultura, por características sociodemográficas (\%). *

\begin{tabular}{cccccc}
\hline \multicolumn{3}{c}{ Educación } & \multicolumn{3}{c}{ Cultura } \\
\cline { 2 - 6 } $\begin{array}{c}\text { Demasiado } \\
\text { poco }\end{array}$ & Suficiente & Demasiado & $\begin{array}{c}\text { Demasiado } \\
\text { poco }\end{array}$ & Suficiente & Demasiado \\
\hline
\end{tabular}

\section{Edad}

$\begin{array}{lllllll}\text { De 18 a 25 años } & 51,5 & 44,2 & 4,3 & 52,1 & 42,9 & 5,0 \\ \text { De 26 a 40 años } & 56,4 & 40,8 & 2,9 & 56,7 & 40,4 & 2,9 \\ \text { De 41 a 60 años } & 55,2 & 41,9 & 2,9 & 55,8 & 41,5 & 2,7 \\ \text { Más de 60 años } & 45,1 & 50,8 & 4,2 & 45,4 & 50,8 & 3,8 \\ \text { Nivel educativo } & & & & & & \\ \text { Sin estudios } & 45,1 & 50,2 & 4,7 & 46,0 & 49,2 & 4,7 \\ \text { Estudios Primarios } & 53,4 & 44,0 & 2,7 & 53,5 & 43,7 & 2,8 \\ \text { Formación Profesion. 52,8 } & 43,9 & 3,3 & 53,1 & 42,7 & 4,3 \\ \text { Bachiller } & 55,6 & 40,8 & 3,6 & 54,5 & 42,3 & 3,2 \\ \text { Universitarios } & 61,1 & 35,9 & 2,9 & 63,4 & 34,3 & 2,3\end{array}$

Religiosidad (1=No practicante; 5=Muy practicante)

$\begin{array}{lllllll}1 & 54,7 & 42,1 & 3,2 & 56,5 & 39,9 & 3,6 \\ 2 & 50,9 & 46,0 & 3,1 & 51,1 & 45,5 & 3,4 \\ 3 & 50,9 & 45,6 & 3,5 & 50,3 & 46,7 & 3,1 \\ 4 & 50,9 & 45,2 & 3,9 & 49,4 & 47,4 & 3,3 \\ 5 & 50,7 & 44,6 & 4,7 & 54,0 & 42,2 & 3,8\end{array}$

Ideología

$\begin{array}{lrrrrrr}\text { Extrema Izquierda } & 61,4 & 29,5 & 9,0 & 73,0 & 20,4 & 6,6 \\ \text { Izquierda } & 54,2 & 42,7 & 3,1 & 55,3 & 42,0 & 2,7 \\ \text { Centro Izquierda } & 49,0 & 46,9 & 4,0 & 50,9 & 45,9 & 3,2 \\ \text { Centro } & 49,4 & 47,2 & 3,4 & 51,0 & 44,4 & 4,6 \\ \text { Centro Derecha } & 54,8 & 42,1 & 3,2 & 52,7 & 43,4 & 3,9 \\ \text { Derecha } & 53,4 & 42,4 & 4,2 & 51,8 & 44,6 & 3,6 \\ \text { Extrema Derecha } & 59,3 & 28,2 & 12,5 & 39,3 & 45,5 & 15,3\end{array}$

Clase social subjetiva

\begin{tabular}{llrrrrr} 
Alta & 41,7 & 20,8 & 37,5 & 58,3 & 41,7 & 0,0 \\
Media alta & 58,5 & 35,2 & 6,3 & 62,0 & 32,6 & 5,4 \\
Media media & 54,3 & 42,8 & 3,0 & 53,7 & 42,9 & 3,3 \\
Media baja & 49,8 & 46,6 & 3,6 & 52,0 & 44,2 & 3,9 \\
Baja & 50,8 & 45,2 & 4,0 & 50,0 & 47,5 & 2,5 \\
\hline
\end{tabular}

* Los porcentajes representan la media del periodo analizado (1991-1996) para cada categoría. Fuente: Encuestas de Cultura Política y Económica del CIRES (1991-1996). 
religiosa con los más insatisfechos con el volumen de gasto. Una correlación más estrecha se observa en el caso de la ideología. Conforme nos desplazamos más a la izquierda de la escala ideológica se incrementa considerablemente el porcentaje de los que juzgan el gasto en desempleo como insuficiente, especialmente en los grupos de extrema izquierda. Detrás de esto se deja traslucir una actitud más crítica con el funcionamiento de nuestro sistema económico en general y que se verifica en otros indicadores.

\section{Ayuda a las clases bajas}

La ayuda a los grupos más desfavorecidos de la sociedad, junto con una mayor redistribución de la riqueza, constituye uno de los objetivos declarados de la mayoría de las políticas sociales. En el imaginario colectivo español, en el que se considera que las desigualdades sociales son demasiado profundas, atribuyendo paralelamente la responsabilidad de eliminarlas al Estado, la cuestión de la ayuda a las clases bajas tiene una gran importancia. Según la reseñada encuesta del CIRES de 1994, un $71 \%$ de los españoles piensa que el Estado es responsable de paliar las situaciones de necesidad (gráfico 2), una opinión que volvió a ser suscrita por un $70 \%$ de la población con ocasión de la encuesta de bienestar de la ONCE en 1996.

De acuerdo con estas percepciones, la ayuda a las clases bajas es una de las partidas del gasto social que se encuentra peor dotada según los españoles. Un porcentaje constante a lo largo de la década de los noventa, en torno al $73 \%$ o $74 \%$ de los encuestado opina que el gasto en ayuda a las clases bajas es demasiado poco, por oposición a un porcentaje variable entre $15 \%$ y $18 \%$ que lo consideran suficiente. En 1994, no obstante, el porcentaje de los que opinaban que el gasto era demasiado poco descendió hasta el $71 \%$, situándose el grupo de los que lo juzgaban suficiente en el $22 \%$ (gráfico 3 ).

Existen diferencias notables en cuanto a la actitud ante el gasto público destinado al socorro de los menos favorecidos de la sociedad (tabla 3). Se observa una relación lineal con la edad, de forma que son los grupos de menos edad, de 18 a 25 años, y particularmente de 26 a 40 años, los que califican como más insuficiente la atención presupuestaria a este colectivo.

Correlativamente, son los grupos de mayor nivel educativo los que manifiestan que el gasto destinado a las clases bajas es más escaso. La ideología y el nivel de práctica religiosa tienen unos efectos menos claros sobre la actitud hacia esta partida de los gastos sociales. No obstante, se observa que los grupos de menor práctica religiosa, así como los que se sitúan más cercanos a la extrema izquierda, tienen un talante más crítico ante el montante de dinero que las administraciones públicas dedican a las clases bajas, dejando entrever, nuevamente, su posición crítica con el sistema económico. Por lo que respecta a la clase social subjetiva, quienes se ubican en la clase media-media lo consideran más insufi- 
Tabla 3.

Actitudes de los españoles hacia el gasto público en desempleo y ayuda a las clases bajas, por características sociodemográficas (\%). *

\begin{tabular}{lcccccc}
\hline & \multicolumn{3}{c}{ Desempleo } & \multicolumn{3}{c}{ Ayuda a clases bajas } \\
\cline { 2 - 7 } & $\begin{array}{c}\text { Demasiado } \\
\text { poco }\end{array}$ & Suficiente & Demasiado & $\begin{array}{c}\text { Demasiado } \\
\text { poco }\end{array}$ & Suficiente Demasiado \\
\hline Edad & & & & & & \\
& & & & & & \\
De 18 a 25 años & 70,9 & 25,0 & 4,1 & 80,2 & 17,6 & 2,2 \\
De 26 a 40 años & 67,5 & 27,7 & 4,8 & 81,6 & 16,3 & 2,1 \\
De 41 a 60 años & 64,4 & 29,5 & 6,1 & 78,9 & 19,1 & 2,0 \\
Más de 60 años & 63,2 & 31,1 & 5,7 & 74,9 & 22,3 & 2,8 \\
Nivel educativo & & & & & & \\
Sin estudios & 65,0 & 29,4 & 5,6 & 75,3 & 21,3 & 3,4 \\
Estudios Primarios & 68,7 & 26,3 & 5,0 & 79,2 & 19,2 & 1,6 \\
Formación Profesional & 66,7 & 28,6 & 4,8 & 80,9 & 17,0 & 2,1 \\
Bachiller & 64,9 & 30,0 & 5,1 & 81,1 & 17,0 & 1,8 \\
Universitarios & 63,5 & 30,7 & 5,8 & 81,4 & 16,4 & 2,2
\end{tabular}

Religiosidad (1=No practicante; 5=Muy practicante)

$\begin{array}{lllllll}1 & 69,3 & 26,2 & 4,5 & 83,1 & 15,4 & 1,5 \\ 2 & 65,6 & 28,4 & 5,9 & 78,0 & 19,5 & 2,4 \\ 3 & 65,8 & 28,5 & 5,7 & 76,8 & 20,6 & 2,6 \\ 4 & 62,7 & 32,3 & 5,0 & 74,2 & 23,0 & 2,8 \\ 5 & 63,2 & 30,3 & 6,5 & 76,8 & 20,1 & 3,0\end{array}$

Ideología

$\begin{array}{lllllll}\text { Extrema Izquierda } & 70,3 & 25,4 & 4,2 & 78,7 & 14,9 & 6,4 \\ \text { Izquierda } & 69,5 & 26,3 & 4,2 & 82,6 & 15,9 & 1,5 \\ \text { Centro Izquierda } & 61,9 & 33,3 & 4,7 & 78,3 & 18,8 & 2,9 \\ \text { Centro } & 62,0 & 32,6 & 5,3 & 73,4 & 23,1 & 3,5 \\ \text { Centro Derecha } & 58,1 & 35,1 & 6,9 & 75,1 & 23,5 & 1,4 \\ \text { Derecha } & 63,7 & 27,8 & 8,4 & 77,9 & 19,3 & 2,8 \\ \text { Extrema Derecha } & 60,9 & 24,2 & 14,9 & 66,0 & 25,7 & 8,3\end{array}$

Clase social subjetiva

\begin{tabular}{lllllll} 
Alta & 63,9 & 30,6 & 5,6 & 66,7 & 33,3 & 0,0 \\
Media alta & 62,0 & 28,7 & 9,4 & 76,4 & 20,1 & 3,5 \\
Media media & 66,7 & 28,1 & 5,2 & 80,8 & 17,3 & 1,9 \\
Media baja & 65,7 & 29,3 & 5,1 & 77,5 & 19,7 & 2,8 \\
Baja & 65,2 & 29,8 & 5,1 & 76,4 & $.21,7$ & 1,9 \\
\hline
\end{tabular}

* Los porcentajes representan la media del periodo analizado (1991-1996) para cada categoría. Fuente: Encuestas de Cultura Política y Económica del CIRES (1991-1996). 
ciente, por oposición al grupo de clase alta, entre quienes se da la menor proporción de españoles que lo califican como insuficiente.

\section{Vivienda}

A pesar de que las políticas de vivienda no forman parte del cuerpo tradicional de las políticas sociales es importante analizar las actitudes de los españoles en este aspecto por varios motivos. La vivienda es una de las cuestiones que ha preocupado tradicionalmente a los españoles. En este caso confluyen una serie de factores que han hecho de la vivienda un problema español endémico, especialmente para la juventud. A ello se añade una cultura de vivienda en propiedad, que ha hecho que se desarrolle un precario mercado de vivienda en alquiler, que es insuficiente a todas luces para facilitar, entre otras cosas, la emancipación familiar de los jóvenes.

El derecho a una vivienda digna está también plasmado en la Constitución española en su artículo 47. Y los ciudadanos igualmente demandan la atención del Estado en este área de las políticas sociales. Según la citada encuesta del CIS, en 1996 un 68\% de los españoles se mostraba de acuerdo con que el gobierno facilitara una vivienda a las personas con pocos ingresos. $Y$ en 1994, en respuesta a una encuesta del CIRES, un $76 \%$ decía que el Estado era el responsable de garantizar el derecho a tener una vivienda digna (gráfico 2), idéntico porcentaje al que suscribió esta misma afirmación en la encuesta de bienestar de la ONCE.

Esto se refleja en que el gasto del Estado en vivienda es uno de los que peor se evalúan por los ciudadanos. Es la partida presupuestaria que consideran más insuficiente detrás de la ayuda a las clases bajas, aunque en los años 1995 y 1996 el porcentaje de los que opinaban que el gasto era demasiado reducido decreció considerablemente, situándose al nivel de los que consideraban que el gasto en desempleo era demasiado bajo. En 1991 los que opinaban que el montante del gasto en vivienda era demasiado reducido eran un $73 \%$, con un $17 \%$ que lo consideraban suficiente. En 1996 los que seguían manteniendo la insuficiencia del gasto en vivienda eran ya un $64 \%$, con un $28 \%$ que sostenían que el gasto era suficiente (gráfico 3).

A pesar de que el problema de la vivienda se encuentra bastante extendido en la sociedad española y de que no tiene unas connotaciones ideológicas claras, se observan algunas diferencias de interés en la distribución de las actitudes de los españoles ante el gasto público en vivienda (tabla 4). Por edades, el grupo de más de 60 años aparece como el más benevolente en comparación con el resto. Sólo un $69,7 \%$ de este grupo considera que el gasto público en vivienda es demasiado bajo, por oposición al 78,8\% que piensa así en el grupo de 26 a 40 años. Este es el grupo más crítico, al ser el que presenta las necesidades de vivienda más importantes, pues coincide con la edad de emancipación de los jóvenes y cubre la edad de formación y consolidación de la propia familia. 
También hay diferencias apreciables en función del nivel educativo. Puede decirse que conforme se incrementa el nivel de formación, se incrementa la percepción de que el gasto en vivienda es demasiado escaso. Igualmente, se da una importante asociación con la variable de práctica religiosa. Los que declaran una menor práctica religiosa, acostumbran a ser el grupo más insatisfecho con el gasto público en vivienda.

Siguiendo una pauta habitual, los grupos ideológicamente más extremos, de izquierda y de derecha, son los más proclives a juzgar como insuficiente el gasto en vivienda, si bien hay que resaltar que los que se ubican en la extrema izquierda se muestran considerablemente más insatisfechos. Por clase social, los más insatisfechos son quienes se ubican en las clases medias, un colectivo en el que la vivienda ha sido vista tradicionalmente como un símbolo de status.

\section{ACTITUDES DE LOS ESPAÑOLES HACIA LAS POLÍTICAS SANITARIAS}

La sanidad y la protección pública del derecho a la salud ha sido otro de los pilares tradicionales del Estado de Bienestar. No obstante, se analizan separadamente de las políticas sociales del Estado de Bienestar en orden a una mejor sistemática y mayor claridad expositiva. La sanidad pública trató, en un principio, de garantizar una protección pública frente a la enfermedad profesional del trabajador, pero este derecho se extendió progresivamente a las enfermedades de índole no profesional y a la familia del trabajador. La extensión universal de la cobertura sanitaria ha constituido, por tanto, un reto importante para numerosos países en las pasadas décadas, una tarea que no quedó completada en España hasta épocas relativamente recientes, dando así cumplimiento al mandato contenido en el artículo 43 de la Constitución de 1978.

Sin embargo, una vez completada la universalización de la cobertura sanitaria, la mejora de la calidad de los servicios de salud es otro desafío importante con el que se enfrentan las administraciones sanitarias de nuestros días. También en este ámbito se ha producido un importante incremento presupuestario, desde menos del medio billón de pesetas en 1978 hasta más de tres billones de pesetas en 1995 (Barrada y Gonzalo, 1998). Los españoles apoyan igualmente una intervención activa y decidida de los poderes públicos en un ámbito tan sensible como el de la sanidad. Según una encuesta del CIS de 1996, el 80\% opinaban que el Estado, sin duda, tenía que garantizar una asistencia sanitaria para todos los ciudadanos. Y en 1994, en otra encuesta del CIRES, el 53\% de la población decía que el Estado era el responsable de garantizar el derecho al cuidado médico (gráfico 2), una opinión compartida por el $45 \%$ de los entrevistados en la citada encuesta de la ONCE de 1996.

De todas formas, tras el estudio de las actitudes hacia el gasto en sanidad, se observa que entre los años de 1991 y 1996 se produce un descenso en el grupo de 
Tabla 4.

Actitudes de los españoles hacia el gasto público en vivienda, por características sociodemográficas (\%).*

\begin{tabular}{lll}
\hline Demasiado poco & Suficiente & Demasiado \\
\hline
\end{tabular}

\section{Edad}

De 18 a 25 años

$\begin{array}{lll}74,8 & 22,4 & 2,7 \\ 78,8 & 19,6 & 1,6 \\ 75,6 & 22,6 & 1,8 \\ 69,7 & 27,2 & 3,1\end{array}$

De 41 a 60 años $\quad 75,6$

27,2

, 6

Más de 60 años

Nivel educativo

$\begin{array}{llll}\text { Sin estudios } & 70,7 & 26,4 & 2,9 \\ \text { Estudios Primarios } & 76,3 & 21,8 & 2,0 \\ \text { Formación Profesional } & 74,8 & 22,9 & 2,3 \\ \text { Bachiller } & 75,8 & 22,2 & 2,0 \\ \text { Universitarios } & 80,2 & 18,4 & 1,5\end{array}$

Religiosidad (1=No practicante; 5=Muy practicante)

$\begin{array}{llll}1 & 79,0 & 18,7 & 2,3 \\ 2 & 74,6 & 23,2 & 2,2 \\ 3 & 72,1 & 26,0 & 1,9 \\ 4 & 70,1 & 28,0 & 1,9 \\ 5 & 73,8 & 23,4 & 2,8\end{array}$

\section{Ideología}

$\begin{array}{llll}\text { Extrema Izquierda } & 87,5 & 12,5 & 0,0 \\ \text { Izquierda } & 77,7 & 20,3 & 2,0 \\ \text { Centro Izquierda } & 73,5 & 24,3 & 2,1 \\ \text { Centro } & 71,3 & 26,3 & 2,4 \\ \text { Centro Derecha } & 68,5 & 28,8 & 2,6 \\ \text { Derecha } & 74,5 & 22,7 & 2,9 \\ \text { Extrema Derecha } & 75,1 & 20,7 & 4,2\end{array}$

Clase social subjetiva

$\begin{array}{llll}\text { Alta } & 44,4 & 38,9 & 16,7 \\ \text { Media alta } & 77,2 & 20,4 & 2,4 \\ \text { Media media } & 76,6 & 21,5 & 1,9 \\ \text { Media baja } & 74,3 & 23,5 & 2,2 \\ \text { Baja } & 69,7 & 27,2 & 3,0\end{array}$

* Los porcentajes representan la media del periodo analizado (1991-1996) para cada categoría. Fuente: Encuentas de Cultura Política y Económica del CIRES (1991-1996). 
los que sostienen que el gasto es demasiado reducido. En 1991 este grupo representaba un $65 \%$, frente al $24 \%$ que consideraba que el gasto era suficiente. En 1996 los porcentajes eran del 58\% y del 33\%, respectivamente (gráfico 3). Como puede verse se trata de un cambio importante en las preferencias de gasto en esta partida de las políticas sociales.

La relación de las actitudes hacia el gasto sanitario con las variables sociodemográficas aparece bastante confusa (tabla 5). No obstante, las mujeres parecen percibir de forma más crítica que los hombres el volumen de gasto en sanidad. La edad también mantiene una relación en forma de U con las actitudes hacia el gasto sanitario. Los más jóvenes y los más mayores son los que más satisfechos se manifiestan en relación con el mismo, mientras que los grupos de edades intermedias son quienes lo califican como más insuficiente.

El nivel educativo no ejerce una gran influencia sobre las actitudes hacia el gasto en las políticas sanitarias, si bien son los titulados de enseñanzas medias, Bachiller y Formación Profesional, los que consideran que el gasto en educación es más insuficiente. De la misma forma, la variable de práctica religiosa apenas condiciona la distribución de las actitudes hacia el gasto en sanidad.

$\mathrm{Ni}$ siquiera la ideología parece correlacionarse estrechamente con la actitud hacia el gasto sanitario. De acuerdo con la pauta general, descrita al analizar la distribución ideológica de las actitudes hacia el gasto social, son los grupos más extremos ideológicamente los que manifiestan una mayor insatisfacción con el volumen de gasto dedicado a la sanidad. En este caso, sin embargo, son los que se ubican en la extrema derecha los que consideran en mayor proporción que el gasto de las administraciones públicas en sanidad es demasiado escaso.

Por clases sociales, es el grupo de los que se autocalifican dentro de la clase media-alta el que cuenta con una mayor frecuencia de evaluaciones insatisfactorias del montante del gasto sanitario, por oposición a quienes se ubican en la clase baja, y particularmente quienes se ubican en la clase alta, grupo en el que predominan los que califican el gasto sanitario como suficiente.

\section{ACTITUDES SOBRE LA CALIDAD DE LOS SERVICIOS DE BIENESTAR SOCIAL}

Como ya se ha mencionado, los ciudadanos de las sociedades occidentales, en general, tienen una visión bastante crítica de la gestión de los servicios públicos por parte de los gobiernos. Los españoles responden también a este perfil, pero con una nota probablemente distintiva. Y es que para ellos existe, además, un agravio comparativo entre los servicios públicos y las prestaciones sociales que reciben y los que gozan los ciudadanos de los países de su entorno, que consideran más avanzados, aun a pesar de que un elevado porcentaje dice no conocer bien la situación real. Según datos del CIRES de 1994, un porcentaje 
Tabla 5.

Actitudes de los españoles hacia el gasto público en sanidad, por características sociodemográficas (\%). *

\begin{tabular}{rll}
\hline Demasiado poco & Suficiente & Demasiado \\
\hline
\end{tabular}

\section{Edad}

De 18 a 25 años

De 26 a 40 años

64,3

32,3

28,1

3,4

De 41 a 60 años

68,2

28,0

3,8

Más de 60 años

55,6

37,0

5,9

7,4

\section{Nivel educativo}

Sin estudios

$58,9 \quad 33,7$

$65,4 \quad 29,8$

Estudios Primarios

65,4

Formación Profesional

67,3

66,3

29,8

30,1

29,4

64,4

31,4

7,4

4,8

Bachiller

Religiosidad (1=No practicante; 5=Muy practicante)

$\begin{array}{llll}1 & 66,0 & 29,2 & 4,8 \\ 2 & 64,0 & 30,7 & 5,3 \\ 3 & 64,1 & 30,8 & 5,1 \\ 4 & 59,8 & 34,3 & 5,8 \\ 5 & 64,8 & 29,0 & 6,2\end{array}$

Ideología

$\begin{array}{llll}\text { Extrema Izquierda } & 66,4 & 24,4 & 9,2 \\ \text { Izquierda } & 63,9 & 31,7 & 4,4 \\ \text { Centro Izquierda } & 61,6 & 33,6 & 4,9 \\ \text { Centro } & 62,1 & 32,2 & 5,7 \\ \text { Centro Derecha } & 64,8 & 29,3 & 5,9 \\ \text { Derecha } & 64,3 & 29,5 & 6,2 \\ \text { Extrema Derecha } & 69,9 & 24,9 & 5,2\end{array}$

Clase social subjetiva

\begin{tabular}{llrr} 
Alta & 34,7 & 40,3 & 25,0 \\
Media alta & 68,2 & 28,4 & 3,4 \\
Media media & 64,7 & 30,6 & 4,7 \\
Media baja & 63,4 & 31,2 & 5,4 \\
Baja & 60,8 & 32,2 & 6,9 \\
\hline
\end{tabular}

* Los porcentajes representan la media del periodo analizado (1991-1996) para cada categoría. Fuente: Encuestas de Cultura Política y Económica del CIRES (1991-1996). 
superior al 20\% decían no saber si los servicios en España eran peores o mejores que en el resto de Europa (gráfico 4).

En general, no obstante, la visión de los españoles respecto de los servicios que reciben, en términos comparativos, es bastante negativa. En todos los casos quienes manifiestan que los servicios son peores que en Europa superan el $50 \%$ de las respuestas válidas. En sentido contrario, los que opinan que los servicios en España son mejores que en Europa representan porcentajes bastante pequeños. A pesar de que no existen diferencias sustanciales en la evaluación de cada uno de los servicios, la sanidad es el servicio peor valorado comparativamente con el resto de Europa. Un 48\% del total de los entrevistados manifestaba que era peor en España, mientras sólo al $4 \%$ les parecía mejor y un $27 \%$ opinaba que la sanidad española estaba a la altura del resto de Europa (gráfico 4).

Sin embargo, cuando comparamos los servicios públicos actuales en España con los del pasado reciente emerge una actitud positiva. En 1995 un 60\% de los españoles consideraba que durante la década anterior los servicios y las prestaciones públicas habían mejorado, aunque este porcentaje se redujo al $48 \%$ en 1996 y en 1997 llegaba hasta el 55 \% (Delgado y San Vicente, 1998). Entrando en el detalle de cada uno de los servicios concretos, merece la pena destacar que, según una encuesta del CIS de 1997, un 65\% de los españoles pensaba que la sanidad era mejor que hace diez años, un $62 \%$ opinaba lo mismo de la educación y un $59 \%$ de los servicios sociales.

Pero más allá de reconocer la evolución positiva de las prestaciones y de los servicios en los últimos años, los españoles juzgan de forma bastante crítica la forma en que funcionan los servicios públicos y las prestaciones sociales en la actualidad. Según datos del Instituto de Estudios Fiscales (1998), en 1997 sólo un $16 \%$ de los españoles pensaba que funcionan correctamente, mientras que un $82 \%$ opinaba que algunos servicios deberían ser mejorados sustancialmente. En concreto, un $76 \%$ pensaba que la sanidad debería ser mejorada, un $57 \%$ pensaban lo mismo de la política de empleo y, en porcentajes más reducidos, un 38\% pensaba que debería mejorarse la educación y un $32 \%$ la protección social.

Por otro lado, los españoles siguen pensando que los impuestos que han de pagar se adecúan bastante mal al nivel de servicios y prestaciones que les ofrece el Estado. En 1995, un 79\% pensaba que se adecuaban poco o nada, si bien en 1997 este grupo representaba un 59\%. En cualquier caso, a pesar de esta mejoría en la percepción de la relación impuestos-servicios, las principales críticas sobre los casos de mal funcionamiento de los servicios públicos se dirigen contra la mala gestión de los recursos (Instituto de Estudios Fiscales, 1995; 1997; 1998).

Un 76\% en 1996 y un 73\% en 1997 opinaban que lo que habría que hacer para solucionar los problemas de funcionamiento de los servicios es administrar de forma más eficiente el dinero recaudado y mejorar la gestión de forma sustancial. Sólo el $18 \%$ de los entrevistados se mostraba partidario de resolver los problemas que tienen planteados los servicios públicos restringiendo el acceso a 


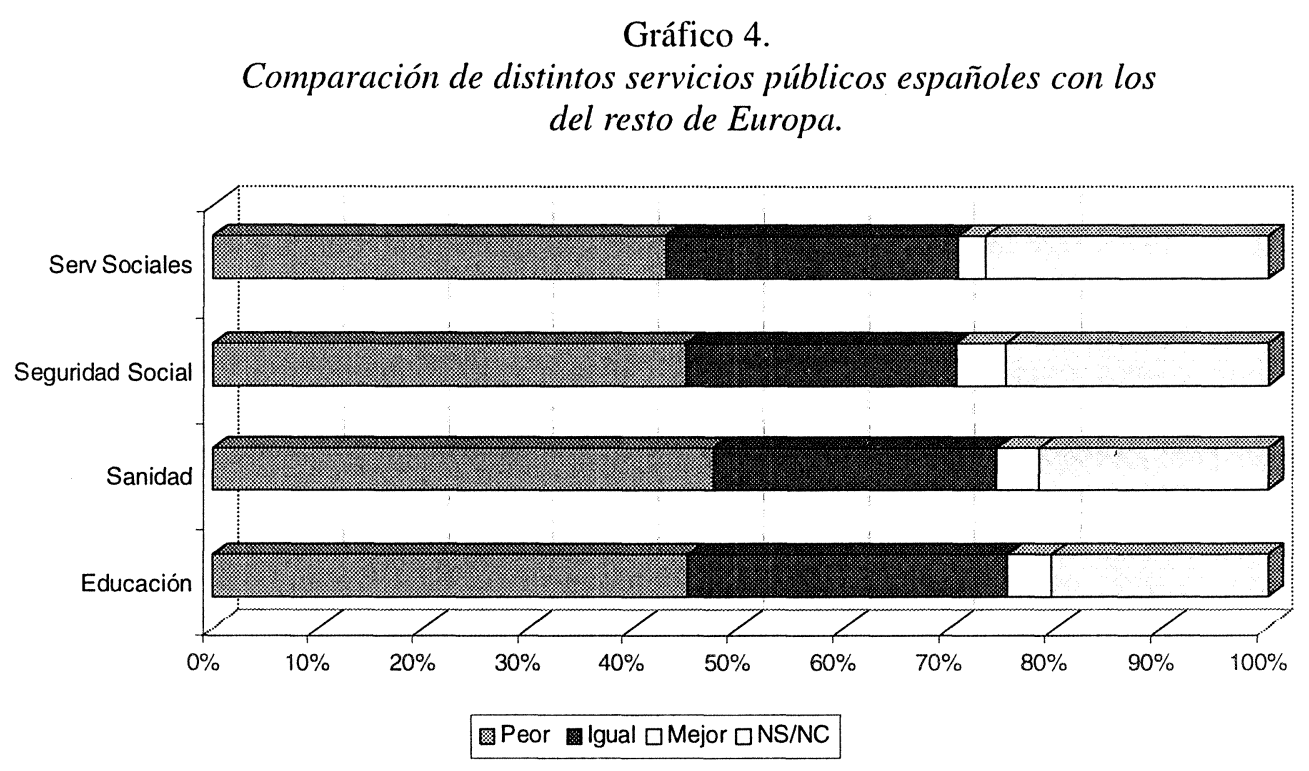

Fuente: Encuesta de Bienestar Social del CIRES (1994).

los mismos a las personas que verdaderamente los necesiten. Y la opción de reducir servicios era absolutamente minoritaria (Delgado y San Vicente, 1998).

Los datos del Instituto de Estudios Fiscales $(1997 ; 1998)$ muestran nuevamente el sentimiento de agravio comparativo con respecto a otros países de Europa, a pesar del poco conocimiento declarado de la fiscalidad en esos países. Un porcentaje de más del $21 \%$ decía en 1996 y 1997 no saber si la adecuación entre impuestos y servicios era mejor en España que en otros países europeos. No obstante, un 48\% en 1996 y un 45\% en 1997 sostenían que la relación impuestos-servicios era peor en España que en Europa.

A pesar de que esta visión de conjunto parece bastante negativa, la evaluación de los servicios concretos arroja algunos elementos positivos. Según datos del CIS, un 54\% de los españoles pensaba en 1997 que la enseñanza funciona con mucha o bastante eficiencia. Un 53\% pensaba lo mismo de la sanidad y un $46 \%$ respecto de los servicios sociales. Y los porcentajes se mantenían relativamente estables o mejorando con respecto a los años 1992, 1994 y 1996 en los que se había realizado la misma pregunta. Desde otro punto de vista, resulta en cualquier caso preocupante que alrededor de la mitad de los ciudadanos españoles opinen que la mayoría de los servicios esenciales que presta el Estado funcionan con poca o ninguna eficiencia. 
Por último, otro dato interesante es la valoración que los españoles hacen de las instituciones prestadoras de los servicios públicos. En una encuesta del CIRES de 1994 se preguntaba por la valoración de algunas de estas instituciones. Por lo que se refiere a las organizaciones dependientes de entes públicos, se mencionaban el INSERSO, el Instituto de la Mujer y el Instituto de la Juventud. Lo primero que destaca del análisis de estos datos es el poco conocimiento que los españoles dicen tener de estas instituciones. Un 31\% decía no conocer el INSERSO, un 51\% tampoco conocía el Instituto de la Mujer y otro $60 \%$ no conocía el Instituto de la Juventud. Quienes sí conocían estas instituciones daban una puntuación ligeramente por encima del aprobado para las tres. La media de valoración era del 6,3 para el INSERSO, del 6,4 para el Instituto de la Mujer y del 6,6 para el Instituto de la Juventud.

\section{CONCLUSIONES}

Las actitudes de los españoles respecto de las políticas sociales se han mantenido relativamente estables a lo largo de los últimos años, algo que concuerda con las tendencias descritas en la mayoría de los países del entorno. Una nota distintiva de la sociedad española es el gran énfasis que se pone en el Estado como ente responsable de nivelar las desigualdades de una sociedad que se considera demasiado injusta. Y obviamente esto afecta a la forma en que se percibe y se evalúa la intervención del Estado en las distintas áreas de la política social.

Pero, junto a ese énfasis en la intervención del Estado como gran benefactor, se confía poco en sus posibilidades para cumplir con las altas expectativas que los españoles depositan en él. Básicamente, porque se le considera un "mal gestor de asuntos y de dineros" (Delgado y San Vicente, 1998). Y, en efecto, los españoles consideran que los problemas que tienen planteados los servicios de provisión pública podrían ser resueltos con una gestión más eficiente antes que con medidas que atajasen el fraude en la percepción indebida de servicios y prestaciones.

Respecto de las políticas sociales concretas, el nivel de apoyo al incremento del gasto en cada una de las partidas presupuestarias analizadas es similar también al de otros países del entorno. Porcentajes que se sitúan generalmente entre el $60 \%$ y el $70 \%$ opinan que el Estado debería incrementar el gasto en estas políticas. Salvo en el caso de educación y cultura, partidas en las que el porcentaje de quienes desean aumentar el volumen de gasto iguala prácticamente al de los que consideran que el volumen de gasto es el idóneo. Esto es congruente con un modelo de sociedad que prima la igualdad de resultados antes que la igualdad de oportunidades.

A diferencia de otras sociedades, como Estados Unidos, en donde el mayor énfasis se pone en las políticas educativas como medio de igualar las desigualda- 
des provocadas por la sociedad, en España prima la concepción de que debe haber unos estándares de nivel de vida que deben ser asegurados para todos los ciudadanos, con independencia de su nivel de esfuerzo o competencia. Según muestran algunos estudios internacionales, España es comparativamente uno de los países en donde la competitividad interpersonal es menos apreciada.

Otra nota característica de las actitudes de los españoles ante las políticas sociales es que estas actitudes se distribuyen de forma más o menos homogénea a través de todos los segmentos de la sociedad. De los datos analizados se desprende que no existen claras diferencias por grupos sociales o ideológicos en cuanto al apoyo a las políticas sociales. Como ha sido puesto de manifiesto por numerosos autores (inter alia, Toharia, 1989), la mentalidad estatista de los españoles se encuentra extendida, de forma similar, por todos los sectores de la sociedad.

En cualquier caso, un estudio más detallado de estas cuestiones debería dirigirse a estudiar con detenimiento los factores que determinan la preferencia por unas u otras políticas sociales y la forma en la que el status socioeconómico y la ideología de los españoles contribuyen a moldear su percepción de las políticas sociales.

\section{REFERENCIAS BIBLIOGRÁFICAS}

ANDRÉS ORIZO, F. (1994), «Los valores de los españoles», en A. KAIERO (ed.), Valores y estilos de vida de nuestras sociedades en transformación, Universidad de Deusto.

(1996), Sistemas de valores en la España de los noventa, Centro de Investigaciones Sociológicas.

BARRADA RODRÍGUEZ, A. y B. GONZALO GONZÁLEZ (1998), La financiación de la protección social en España, Consejo Económico y Social.

BEAN, Cl. y E. PAPADAKIS (1998), «A Comparison of Mass Attitudes toward the Welfare State in Different Institutional Regimes, 1985-1990», International Journal of Public Opinion Research, Vol. 10.

BELL, D. ([1976] 1994), Las contradicciones culturales del capitalismo, Alianza.

(1977), «The Future World Disorder: The Structural Context of Crisis», Foreing Policy. Vol. 27.

BOTELLA, J. (1994), How much is too much? An Overview of Fiscal Attitudes in Western Europe, Fundación Juan March.

CAMPO, S. del (1995), Valores y Orientaciones Económicas de los Españoles, en AA. VV.: Problemas Económicos Españoles en la Década de los Noventa. Galaxia Gutenberg y Círculo de Lectores.

CENTRO DE INVESTIGACIONES SOCIOLÓGICAS (1997), La cultura económica de los españoles, Centro de Investigaciones Sociológicas. 
(1997), Series temporales: valoración de los servicios públicos, Centro de Investigaciones Sociológicas: Boletín de Datos de Opinión.

CNAAN, R. A. (1989), «Public Opinion and the Dimensions of the Welfare State», Social Indicators Research. Vol. 21.

CNAAN, R.A. et al. (1993), «Cross-Cultural Comparison of Attitudes toward Welfare-State Programs: Path Analysis with Log-Linear Models», Social Indicators Research. Vol. 29.

COUGHLIN, R.M. (1980), Ideology, Public Opinion and Welfare Policy, Institute for International Studies.

DELGADO, M. L. y M. SAN VICENTE (1998), Evolución de la Opinión Fiscal a través de Datos de Encuesta, Instituto de Estudios Fiscales.

EUROBARÓMETRO (1997), L'Opinion des Europeens sur les Services Publics, Comisión de las Comunidades Europeas.

FLORA, P. (ed.) (1986), Growth to Limits: The Western European Welfare States since World War II. Walter de Gruyter.

INSTITUTO DE ESTUDIOS FISCALES (1995), Ciudadanos, contribuyentes y expertos: opiniones y actitudes fiscales de los españoles en 1995, Instituto de Estudios Fiscales.

(1997), Ciudadanos, contribuyentes y expertos: opiniones y actitudes fiscales de los españoles en 1996, Instituto de Estudios Fiscales.

(1998), Ciudadanos, contribuyentes y expertos: opiniones y actitudes fiscales de los Españoles en 1997, Instituto de Estudios Fiscales.

KAASE, M. y K. NEWTON (1995), Beliefs in Government, Oxford University Press.

LADD, E. C. et al. (1979), «The Polls: Taxing and Spending», Public Opinion Quarterly, vol. 43.

LANE, R. E. (1959), «The Fear of Equality», American Political Science Review. Vol. 53.

LÓPEZ PINTOR, R. (1997), «Descontento político y tendencias electorales en Europa», en J.F. TEZANOS, J.M. MONTERO y J.A. DÍAZ (eds.), Tendencias de futuro en la sociedad Española. Primer foro sobre tendencias sociales, Sistema.

MIGUEL, A. de (1998), Opinión pública y coyuntura económica, Instituto de Estudios Económicos.

MORÁN, M. L. y J. BENEDICTO (1995), La cultura política de los españoles, Centro de Investigaciones Sociológicas.

MUÑOZ MACHADO, S., J. L. GARCÍA DELGADO y L. GONZÁLEZ SEARA (dir.) (1997), Las estructuras del bienestar, Civitas.

MURILLO FERROL, F. (1984), "La crisis del estado», en AA.VV.: España: Un Presente para el Futuro (Vol. II: Las Instituciones), Instituto de Estudios Económicos. 
PÉREZ DÍAZ, V. et al. (1997), La opinión pública ante el sistema de pensiones, Servicio de Estudios de La Caixa.

SAMUELSON, R. J. (1995), The Good Life and its Discontents: The American Dream in the Age of Entitlement, 1945-1995, Times Books.

SARTORI, G. (1993), La democracia después del comunismo, Alianza.

SHAPIRO, R.Y. et al. (1987a), «The Polls: Employment and Social Welfare», Public Opinion Quarterly. Vol 51

(1987b), «The Polls: Public Assistance», Public Opinion Quarterly. Vol 51.

SHAPIRO, R.Y. y J.T. YOUNG (1989), «Public opinion and the Welfare State: The United States in Comparative Perspective», Political Science Quarterly, Vol. 104.

SMITH, T.W. (1980), «America's most Important Problem: a Trend Analysis, 1946-1976», Public Opinion Quarterly, Vol. 44

(1980), «General Liberalism and Social Change in Post World War II America: A Sumary of Trends», Social Indicators Research. Vol. 3.

(1987a), «That wich we call welfare by any other name would smell sweeter. An analysis of the impact of question wording on response patterns», Public Opinion Quarterly. Vol. 51.

(1987b), «The polls: The Welfare State in Cross-national Perspective», Public Opinion Quarterly, Vol. 51 .

(1990), «Liberal and conservative trends in the United States since World War II», Public Opinion Quarterly; Vol. 54.

(1995), «Public Support for Public Spending, 1973-1994», Roper Center: The Public Perspective

TAYLOR-GOOBY, P. (1983), Legitimation Deficit, Public Opinion and the Welfare State, Sociology. Vol. 17.

TOHARIA, J.J. (1989), Cambios Recientes en la Sociedad Española. Instituto de Estudios Económicos.

WERT, J. I. (1996), «Sobre cultura política: legitimidad, desafección y malestar», en TUSELL, E. LAMO DE ESPINOSA y R. PARDO (eds.), Entre dos siglos. Reflexiones sobre la Democracia Española. Alianza.

YANKELOVICH, D. (1994), «How Changes in the Economy are reshaping American Values», en H. J. AARON, Th. E. MANN y T. TAYLOR: Values and Public Policy. The Brookings Institution. 
SUMMARY. Although citizens continue asking for an important state's delivery of collective goods and services, during the last two decades there was an increase in the critique toward the management of public services in Western societies. Spanish public opinion about specific welfare state's policies is quite similar to that of other European countries. However, Spaniards claim for a more widespread role of the state in order to reduce social inequalities, because they believe that they live in a society where the richness is very unfairly shared. In addition, they are very unconfident about the state because they think the state handles things badly and unfairly.

E-mail: amjaime@ugr.es 